\title{
Maximal Medical Management: Pushing the Critical Envelope Further
}

\author{
LaBuzetta J N* and Karanjia NP \\ Department of Neurosciences, Division of Neurocritical \\ Care, University of California, USA \\ *Corresponding author: LaBuzetta J N, Department of \\ Neurosciences, Division of Neurocritical Care, University \\ of California, USA
}

Received: July 23, 2017; Accepted: August 07, 2017;

Published: September 26, 2017

\section{Keywords}

Maximal medical management; Neurocritical Care; Code; Herniation

\section{Short Communication}

More recently than neurologists would like to admit, certain diagnoses came with extraordinarily poor prognoses: proximal artery occlusions, aneurysmal subarachnoid hemorrhage, intraparenchymal hemorrhages, intraventricular hemorrhages, to name just a few. Patients with these diagnoses received maximal medical management, but the associated mortality and morbidity was very high despite this management.

Fortunately, over the years, pharmaceutical and technical advances have continually expanded what 'maximal medical management' means, and what it can achieve. In the 1950s, with the more widespread use of ventilators in anesthesia and intensive care units (ICUs), physicians could keep patients alive past the point where neurological decline caused respiratory collapse. Maximal medical management could prolong life, and for patients with neurological emergencies, maximal medical management gave rise to a new field of neurology: Neurocritical care.

In the 1980s, the field of Neurocritical care was born [1]. Academic institutions began to rely on the expertise of neuro Intensivist to provide maximal medical management in the setting of acute brain injury and mitigate complications such as acute respiratory failure, hematoma expansion, central fever, cerebral salt wasting, and intracranial hypertension. The goal was, ultimately, to improve patient outcomes $[2,3]$.

Fast-forward another decade or soto the mid-1990s and the administration of tPA in ischemic stroke was first reported in the New England Journal of Medicine [4]. Now, we routinely give intravenous tPA for ischemic strokes, and 'door-to-needle' times are of utmost importance in comprehensive stroke center certification. We have normothermia, hyperglycemia and dysphagia bundles to improve outcomes [5]. Maximal medical management has continued to evolve, and many trials-including stroke trials [6,7]-compare potentially invasive interventions againstthe ever-changing standard of 'maximal medical management'.
Over the years, some surgical therapies have shown clear benefit over medical management. For instance, now we have the possibility of embolectomy for proximal artery occlusions [8], the use of coiling or clipping to secure aneurysms $[9,10]$, and open and minimally invasive surgical techniques for clot evacuation [11]. In other diagnoses, there is equipoisebetween medical and surgical intervention. However, in some conditions such as cerebral edema, the treatment remains primarily conservative. From a Neurocritical care perspective, there is much to be done to mitigate the intracranial hypertension related tocerebral edema from various etiologies, including stroke: for example, reduction in cerebral blood flow with anesthetics, increased venous drainage, hyperosmolar and hypertonic medications, and normo- or hypothermia [12].

At our institution, we have taken maximal medical management of cytotoxic and vasogenic edema one step further and implemented a hospital-wide "Brain Code" system. This system was adopted in 2012, and is modeled after the now-familiar but once-revolutionary "Stroke Code" [13]. When clinical, neuro monitoring, or radiographic signs of intracranial hypertension or herniation are apparent, a healthcare provider pages a "Brain Code" through the operator, which brings the pharmacist, Neurocritical care physician, and "Brain Code" box to the bedside. Within the first two years of implementation, more than 75 brain codes were called at our institution. The average time to administration of potentially life-saving medication has improved from greater than 40 minutes to 11 minutes in the era of the Brain Code-a highly significant improvement both in terms of statistics and the quality of patient care. When it comes to the brain, time matters [14]. We need to be able to give these medications in the most timesensitive manner possible, and we are using the 'code' model to push the envelope and achieve faster administration.

This system was suggested by the Emergency Neurological Life Support course [12] and called for by neurological academicians $[15,16]$, but we are one of the first academic medical centers to have implemented a formalized brain code process. Using the Brain Code system, we can more effectively manage intracranial crises. We hope other institutions will implement a similar system; without it, medical managementof neurological emergencies simply are not maximized.

\section{References}

1. Wijdicks EF. The history of neurocritical care. Handb Clin Neuro. 2017; 140: 3-14

2. Samuels O, Webb A, Culler S, Martin K, Barrow D. Impact of a dedicated neurocritical care team in treating patients with aneurysmal subarachnoid hemorrhage. Neurocrit Care. 2011; 14: 334-340.

3. Varelas PN, Schultz L, Conti M, Spanaki M, Genarrelli T, Hacein-Bey L. The impact of a neuro-intensivist on patients with stroke admitted to a neurosciences intensive care unit. Neurocrit Care. 2008; 9: 293-299.

4. National Institute of Neurological Disorders and Stroke rt-PA Stroke Study Group. Tissue plasminogen activator for acute ischemic stroke. N Engl J Med. 1995; 333: 1581-1587. 
5. Middleton S, McElduff P, Ward J, Grimshaw JM, Dale S, D'Este C, et al. Implementation of evidence-based treatment protocols to manage fever, hyperglycaemia, and swallowing dysfunction in acute stroke (QASC): a cluster randomised controlled trial. Lancet. 2011; 378: 1699-1706.

6. Chimowitz MI, Lynn MJ, Derdeyn CP, Turan TN, Fiorella D, Lane BF, et al. Stenting versus aggressive medical therapy for intracranial arterial stenosis. N Engl J Med. 2011; 365: 993-1003.

7. Vahedi, K, Hofmeijer J, Juettler E, Vicaut E, George B, Algra A, et al. Early decompressive surgery in malignant infarction of the middle cerebral artery: a pooled analysis of three randomised controlled trials. Lancet Neurol. 2007; 6: 215-222.

8. Nogueira RG, Zaidat OO, Castonguay AC, Haussen DC, Martin CO, Holloway WE, et al. Rescue Thrombectomy in Large Vessel Occlusion Strokes Leads to Better Outcomes than Intravenous Thrombolysis Alone: A 'Real World' Applicability of the Recent Trials. Interv Neurol. 2016; 5: 101-110.

9. Molyneux AJ, Jacqueline Birks, Alison Clarke, Mary Sneade, Richard S C Kerr. The durability of endovascular coiling versus neurosurgical clipping of ruptured cerebral aneurysms: 18 year follow-up of the UK cohort of the International Subarachnoid Aneurysm Trial (ISAT). Lancet. 2015; 385: 691697.

10. Spetzler RF, McDougall CG, Zabramski JM, Albuquerque FC, Hills NK, et al. The Barrow Ruptured Aneurysm Trial: 6-year results. J Neurosurg. 2015 123: 609-617.
11. Mendelow AD, Gregson BA, Rowan EN, Murray GD, Gholkar A, Mitchell $\mathrm{PM}$. Early surgery versus initial conservative treatment in patients with spontaneous supratentorial lobar intracerebral haematomas (STICH II): a randomised trial. Lancet. 2013; 382: 397-408.

12. Stevens RD, Huff JS, Duckworth J, Papangelou A, Weingart SD, Smith WS Emergency neurological life support: intracranial hypertension and herniation. Neurocrit Care. 2012; 1: S60-S65.

13. Rapp K, Bratina P, Barch C, Braimah J, Daley S, Donnarumma R, Kongable $\mathrm{G}$, et al. Code Stroke: rapid transport, triage and treatment using rt-PA therapy. The NINDS rt-PA Stroke Study Group. J Neurosci Nurs. 1997; 29: 361-366

14. Saver JL. Time is brain--quantified. Stroke. 2006; 37: 263-266.

15. Kalanuria AA, Geocadin RG, Puttgen HA. Brain code and coma recovery: aggressive management of cerebral herniation. Semin Neurol. 2013; 33: 133141.

16. Qureshi Al, Suarez JI. More evidence supporting a "brain code" protocol for reversal of transtentorial herniation. Neurology. 2008; 70: 990-991.
Austin J Cerebrovasc Dis \& Stroke - Volume 4 Issue 5 - 2017 ISSN : 2381-9103 | www.austinpublishinggroup.com

LaBuzetta et al. () All rights are reserved
Citation: LaBuzetta JN and Karanjia NP. Maximal Medical Management: Pushing the Critical Envelope Further. Austin J Cerebrovasc Dis \& Stroke. 2017; 4(5): 1070. 